\title{
WORLD BRAIN MEETING The XXII World Congress of Neurology, Santiago, Chile: October 31 - November 5, 2015
}

\author{
Vladimir Hachinski
}

doi:10.1017/cjn.2015.33

Can. J. Neurol. Sci. 2015; 42: 157-158

\section{A Unique, Broad Brain Agenda}

Every other year the neurologists from around the world gather in what has become a World Congress, not only of neurology but of brain science and brain health. As President of the World Federation of Neurology (WFN) (2010-2013) I initiated the foundation of the World Brain Alliance of all the major international brain organizations: European Brain Council (EBC), International Brain Research Organization (IBRO), World Federation of Neurosurgical Societies (WFNS), World Federation of Neurorehabilitation (WFNR), World Federation of Neurology (WFN), World Psychiatry Association (WPA), International Child Neurology Association (ICNA), International League Against Epilepsy (ILAE), World Stroke Organization (WSO), and Alzheimer's Disease International (ADI). This common brain front was visible at the Vienna World Congress of Neurology (September 21-26, 2013) in joint sessions with some of the member organizations and also with the World Health Organization.

The forthcoming World Congress of Neurology reflects the expanded agenda:

- Pierre Magistretti, President of the International Brain Research Organization will be speaking on "Neuroglia Metabolic Coupling: Relevance for Brain Plasticity and Imaging".

- Oleg Chestnov, Assistant Secretary General of the WHO for Non-Communicable Diseases will present an "Integrated Approach to Non-communicable Disorders".

- Emilio Perucca, President of the International League Against Epilepsy will answer the question "Does Mechanism of Action Matter when Selecting Anti-epileptic Drugs?"

- Bo Norrving, past President of the World Stroke Organization will discuss "Strategies to Reduce the Global Burden of Stroke."

- I will address "The Global Challenge of Dementia - Targeting the Vascular Contribution".

- Ingrid Tein, the first Canadian President of the International Child Neurology Association will talk about "An Approach to Epilepsy and Mitochrondrial Disorders of Childhood".

- Levent Küey, Secretary General of the World Psychiatry Association will share his insights about "Depressive and
Anxiety Disorders for the Clinician: Challenges, Diagnosis and Treatment".

- Günther Dueschl, past President of the International Parkinson and Movement Disorder Society and Mark Hallett, President of the International Federation of Clinical Neurophysiology will speak on "The Physiology of Will".

- Giacomo Rizzolati, the discoverer of mirror neurons, will update us in his area "The Mirror Mechanism: New Findings and its Importance in the Organization of the Parietal Lobe".

In addition to these world leaders in the basic and clinical brain sciences, neurologists from around the world will participate, including a new generation of Chilean and Latin American neurologists.

In recognition of the changing nature of our specialty, Morris Freedman, Canada's delegate to the World Federation of Neurology and I are organizing a course on "Careers in Neurology in a Globalizing World" in collaboration with Professor Ricardo Nitrini from Brazil.

\section{Santiago the Magnificent}

Imagine a city at the feet of snowcapped peaks, surrounded by splendid vineyards and hosting a thriving neurological community and you will have glimpsed Santiago. Renato Verdugo, President of the Congress, and his colleagues know that they have a once in a life opportunity to host world neurology and they will let their hospitality shine.

Cultural, social and networking events are planned as well as opportunities for pre- and post-Congress tours ranging in destinations from the dry desert north to the lake rich south with great culinary, cultural and landscape variety in between.

\section{Santiago, Kyoto...Montreal?}

Canada hosted the 1993 World Congress of Neurology in Vancouver organized by Donald Paty and many colleagues from across Canada. Lord Walton of Detchant was President of the World Federation of Neurology and Henry HJM Barnett was the honourary President. Many good things flowed from

\footnotetext{
From the Western University, London Health Sciences Centre, London, Ontario, Canada. Received December 16, 2014. Final Revisions Submitted December 16, 2014.

Correspondence to: Vladimir Hachinski, Western University, London Health Sciences Centre, 339 Windermere Road, London, Ontario, CANADA, N6A 5A5.

(Email: Vladimir.hachinski@lhsc.on.ca)
} 

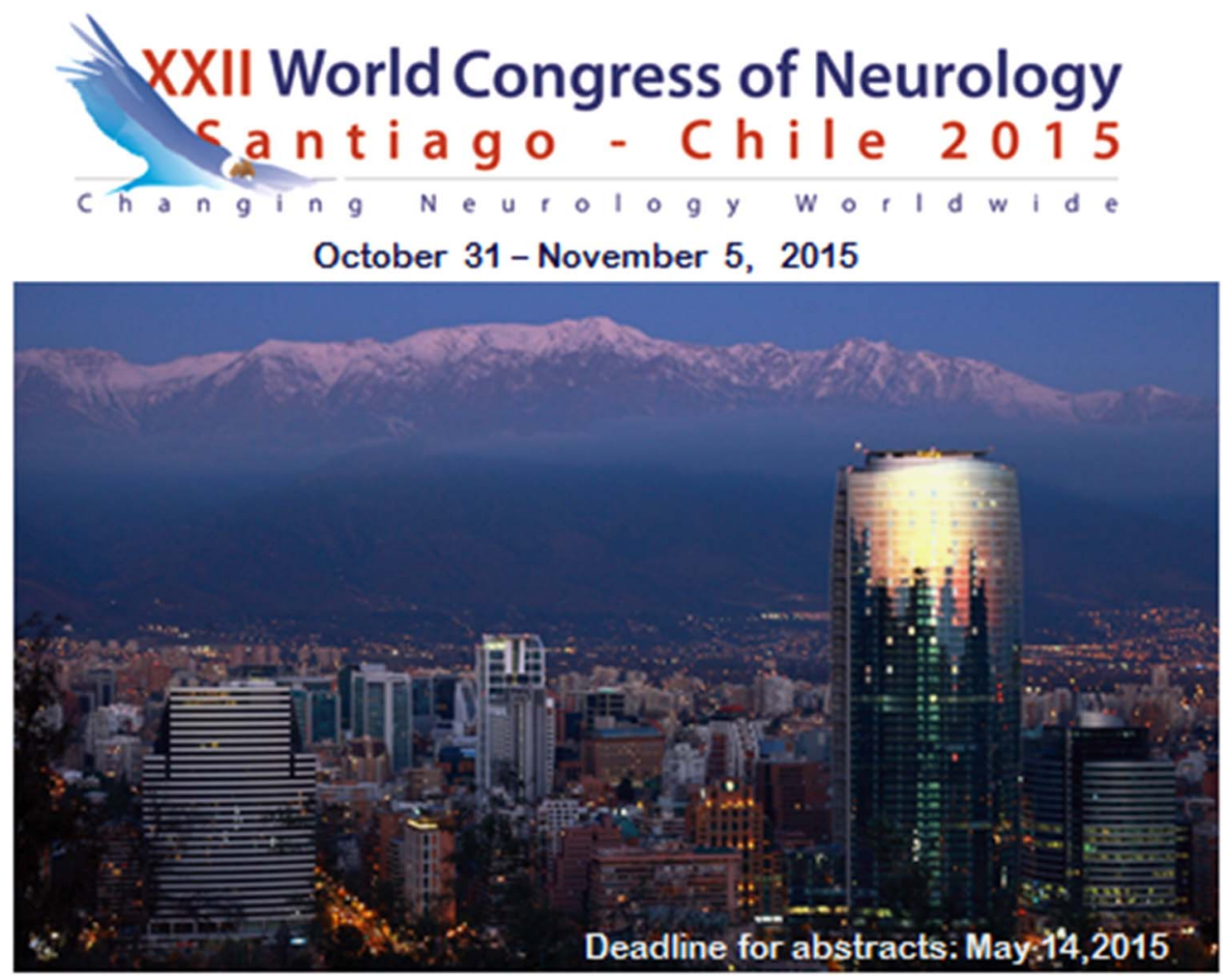

that Congress. We showed what we were doing and learned what others were doing. Friendships, exchanges and collaborations bloomed and the profits of the Congress became the cornerstone capital for a brain foundation.

It may be time for Canadian brain professionals to begin preparing for a bid to host the 2021 World Congress of Neurology, which has become much more than that. The site for 2017 will be in Kyoto, Japan but, if we are to succeed in what has become a very competitive field, we must begin with a strong presence in Santiago.

Come to Santiago and be enlightened, entertained and inspired.

\section{Disclosures}

Vladimir Hachinski does not have anything to disclose. 